\title{
Clinical effectiveness, toxicity, and failure patterns of helical tomotherapy for postoperative oral cavity cancer patients
}

\author{
Chen-Hsi Hsieh ${ }^{1-3}$ \\ Pei-Wei Shueng ${ }^{1,4}$ \\ Li-Ying Wang ${ }^{5}$ \\ Li-Jen Liao ${ }^{6}$ \\ Yu-Chin Lin ${ }^{7}$ \\ Ying-Shiung Kuo ${ }^{8}$ \\ Wu-Chia Lo ${ }^{6}$ \\ Chien-Fu Tseng ${ }^{8}$ \\ Hui-Ju Tien' \\ Hsiu-Ling Chou 9 \\ Yen-Ping Hsieh" \\ Le-Jung $\mathrm{Wu}^{\prime}$ \\ Yu-Jen Chen ${ }^{3,12-14}$
}

'Department of Radiation Oncology, Far Eastern Memorial Hospital, ${ }^{2}$ Department of Medicine, ${ }^{3}$ Institute of Traditional Medicine, School of Medicine, National Yang-Ming

University, ${ }^{4}$ Department of Radiation Oncology,

National Defense Medical Center, ${ }^{5}$ School

and Graduate Institute of Physical Therapy,

College of Medicine, National Taiwan University,

${ }^{6}$ Department of Otolaryngology, ${ }^{7}$ Division of

Medical Oncology and Hematology, Department

of Internal Medicine, ${ }^{8}$ Department of Dentistry

and Oral Surgery, ${ }^{9}$ Department of Nursing,

Far Eastern Memorial Hospital, ${ }^{10}$ Department

of Nursing, Oriental Institute of Technology,

Taipei, "Department of Senior Citizen Service

Management, National Taichung University of

Science and Technology, Taichung, ${ }^{2}$ Department

of Radiation Oncology, ${ }^{13}$ Department of Medical

Research, Mackay Memorial Hospital, ${ }^{14} \mathrm{Graduate}$

Institute of Sport Coaching Science, Chinese

Culture University, Taipei, Taiwan

Correspondence: Yu-Jen Chen

Department of Radiation Oncology,

Mackay Memorial Hospital, 92 Chung

Shan North Road, Taipei 104, Taiwan

Tel +88622809 466I ext 230I

Fax +886228096180

Email chenmdphd@gmail.com

Chen-Hsi Hsieh

Department of Radiation Oncology,

Far Eastern Memorial Hospital,

21 Section 2 Nanya South Road

Banciao, New Taipei 220, Taiwan

Tel +88628966 7000 ext 1033

Fax +886289660906

Email chenciab@gmail.com
This article was published in the following Dove Press journal:

OncoTargets and Therapy

10 March 2014

Number of times this article has been viewed

Background: The outcome of postoperative high- and intermediate-risk oral cavity cancer (OCC) patients receiving helical tomotherapy (HT) remains limited.

Materials and methods: Between November 2006 and November 2012, 53 postoperative high- and intermediate-risk OCC patients treated with HT were enrolled.

Results: The 4-year locoregional, local, and regional control rates were $66 \%, 76.4 \%$, and $94.3 \%$, respectively. The 4-year locoregional control rates of oral tongue and buccal mucosa cancer were $88.3 \%$ and $37.1 \%$, respectively $(P=0.012)$. Eleven (20.8\%) patients experienced locoregional failure. In-field failure occurred in six of $53(11.3 \%)$ in the primary area and three of $53(5.7 \%)$ in the regional lymph-node area. No marginal failure was noted. Two of 53 (3.8\%) experienced out-of-field failure. The rates of grade 3 dermatitis, mucositis, and dysphagia were $11 \%, 34 \%$, and $13 \%$, respectively. No grade 3 xerostomia was noted. Grade 2 xerostomia was $33 \%$ at month 6 and declined to 0 at month 48 . A rate of $56 \%$ of grade 2 trismus at month 6 was noted, and declined to around $30 \%$ after 2 years. No grade 3 trismus was noted after 2 years.

Conclusion: HT as a postoperative modality provided satisfying results, especially for xerostomia and trismus, and was impressive in high- and intermediate-risk OCC patients receiving postoperative HT.

Keywords: concurrent chemoradiation, helical tomotherapy, locoregional control rate, oral cavity cancer, trismus

\section{Background}

Extensive data suggest that intensity-modulated radiation therapy (IMRT) is safe and efficacious in the adjuvant setting for oral cavity cancer (OCC) $\cdot{ }^{1-4}$ Helical tomotherapy (HT) is conceptually regarded as image-guided IMRT. HT was designed and developed with advantages of sharper dose gradients and better normal-tissue sparing compared with step-and-shoot IMRT. According to previous reports, HT plans compared favorably with step-and-shoot IMRT plans regarding sparing of organs at risk and keeping equivalent target-dose homogeneity. ${ }^{5,6}$ Our and other clinical experience of using HT for locally advanced head and neck cancer achieved encouraging results along with less toxicity. ${ }^{7-9}$

Recently, a Phase III trial showed parotid-sparing IMRT caused better recovery of saliva secretion than conventional RT. ${ }^{10}$ In our previous report, HT provided encouraging clinical results for acute xerostomia. ${ }^{8}$ Additionally, Hsiung et al ${ }^{11}$ and Chen et $\mathrm{al}^{12}$ confirmed that radiation-induced trismus progressed over time and was improved by IMRT. However, the longer follow-up data of treatment results and side effects for OCC receiving HT as adjuvant modalities are insufficient. 
Here, we analyze our clinical experience of postoperative OCC patients treated with HT, focusing on locoregional failure patterns, clinical outcome, and toxicity.

\section{Materials and methods}

\section{Patient characteristics}

Between December 2006 and November 2012, 53 patients with oral cavity squamous cell carcinoma (SCC) who had undergone surgery followed by postoperative HT were retrospectively enrolled. Patients treated for recurrences of OCC (including neck recurrences) were excluded from this analysis. Retrospective patient data were collected with the approval of the Institutional Review Board of Far Eastern Memorial Hospital. Staging investigations included complete history and physical examination, fiber-optic endoscopic evaluation, complete blood counts, comprehensive metabolic panel, bone scans, chest X-ray, and computed tomography (CT) or magnetic resonance imaging (MRI) of the head and neck region, which was done before surgery, and a dental evaluation. The disease was staged according to the American Joint Committee on Cancer Staging Classifications, sixth edition, which is based on pathological findings after radical surgery.

\section{Radiation therapy}

RT or concurrent chemoradiation therapy (CCRT) was initiated within 4-6 weeks after operation using $6 \mathrm{MV}$ photons. HT with daily fractions of 1.8 or 2 Gy on 5 consecutive days was prescribed. The frame, fusing, and planning system were applied as per a previous report. ${ }^{8} \mathrm{CT}$ scans with $3 \mathrm{~mm}$ slice thickness were done for treatment planning.

\section{Delineation of target volumes}

The clinical target volumes (CTVs) were determined according to the incidence and location of metastatic neck nodes from various head and neck subsites. ${ }^{13}$ According to the location of the gross tumor and the postoperative flap confirmed using preoperative MRI fused with CT images, CTV1 was defined as the area encompassing both preoperative gross tumor and postoperative flap plus a $0.8-1 \mathrm{~cm}$ margin, which included the resection bed with soft-tissue invasion by the tumor or extracapsular extension (ECE) by metastatic neck nodes truncating air, and uninvolved bones. CTV2 was defined as a high-risk subclinical area, primarily including the pathologically uninvolved cervical lymph nodes, deemed as elective nodal regions, or prophylactically treated neck areas. CTV3 was designated as the low-risk area of potential subclinical disease.
To account for organ motion and patient-setup errors, the planning target volume (PTV)-1 encompassed CTV1 plus a margin of $3 \mathrm{~mm}$, while PTV2 and PTV3 included CTV2 and CTV3 plus a margin of $5 \mathrm{~mm}$, respectively. CTV1 received 60-66 Gy in 30-33 fractions, 64-66 Gy was delivered to highrisk OCC patients, and $60 \mathrm{~Gy}$ was delivered to intermediate-risk OCC patients. For CTV2, 59.4-60 Gy/30-33 fractions were delivered, and for CTV3 51.2-54 Gy/30-33 fractions were delivered. Additionally, no more than $20 \%$ of the PTV received more than $110 \%$ of its prescribed doses, and no more than $1 \%$ of any PTV received less than $93 \%$ of its prescribed doses.

The dose constraints for organs at risk were: 1) brain stem maximum dose 54 Gy; 2) spinal cord maximum dose 45 Gy; 3 ) optic chiasm and optic nerve maximum dose $45 \mathrm{~Gy}$; 4) bilateral parotid glands mean dose $<30 \mathrm{~Gy}$, median dose $<26 \mathrm{~Gy}$, and whole parotid gland volume with $<20$ Gy for that larger than $20 \mathrm{cc}$; 5) two-thirds of glottal larynx $<50 \mathrm{~Gy}$; 6 ) inner ear mean dose $<50 \mathrm{~Gy}$; and 7) mandible maximum dose $70 \mathrm{~Gy}$.

\section{Chemotherapy}

ECE and/or microscopically involved surgical margins were the risk factors for which the impact of CCRT was significant in the two randomized trials (European Organization Research and Treatment of Cancer and Radiation Therapy Oncology Group). There was also a trend in favor of CCRT in the group of patients who had stage III-IV disease, perineural infiltration, vascular embolisms, and/or clinically enlarged level IV-V lymph nodes secondary to tumors arising in the oral cavity or oropharynx. ${ }^{14}$ Therefore, patients with those criteria received concurrent chemotherapy. In addition, if a patient could tolerate chemotherapy, as defined by a Karnofsky performance score of at least 60, a whitecell count of at least $3,500 / \mathrm{mm}^{3}$, a platelet count of at least $100,000 / \mathrm{mm}^{3}$, and a creatinine clearance of more than $50 \mathrm{~mL} /$ minute, then chemotherapy would be prescribed. ${ }^{15}$ During RT, patients who received chemotherapy were treated with cisplatin $\left(30 \mathrm{mg} / \mathrm{m}^{2}\right)$ plus fluorouracil $\left(425 \mathrm{mg} / \mathrm{m}^{2}\right)$ and leucovorin $\left(30 \mathrm{mg} / \mathrm{m}^{2}\right)$, both intravenously each week.

\section{Definition of relapse and delineation of locoregional failure}

When available, imaging studies delineating the site of locoregional failure were fused with the treatment-planning CT scan. Otherwise, anatomic landmarks were used to determine the failure site. If $>95 \%, 20 \%-95 \%$, and $<20 \%$ of volume of recurrent tumor fell within the CTV, the failure was defined as infield, marginal, and out of field, respectively. ${ }^{16}$ 


\section{Follow-up}

All patients were evaluated at least once a week during RT. Upon completion of radiation, patients were then evaluated every 3 months for the first 2 years. At each follow-up visit, a complete evaluation, including clinical examination, bimanual palpation of the oral cavity, and neck palpation, was performed. Posttreatment MRI of the oral cavity and neck was done 1, 3, and 6 months after completion of RT. Acute toxicities (occurring $<90$ days after initiation of RT) and late toxicities (occurring $>90$ days after initiation of RT) were defined and graded according to the Common Terminology Criteria for Adverse Events (CTCAE) version 3. The earliest date of detection of grade 3 or worse toxicity was recorded.

\section{Statistical methods}

Descriptive statistics were calculated to characterize the patients, diseases, and treatment features, as well as toxicities after treatment. Overall survival (OS), disease-free survival (DFS), locoregional control (LRC), and metastasis-free survival (MFS) rates were estimated using the Kaplan-Meier product-limit method and log-rank tests. Durations were calculated from the date of pathologic proof. All analyses were performed using SPSS version 12.0 (SPSS Inc., Chicago, IL, USA).

\section{Results}

\section{Patient characteristics}

Fifty men and three women were enrolled in the study. The mean age was $51 \pm 10.5$ years (range $24-73$ years). The dominant subsets were oral tongue (53\%) and buccal mucosa cancer (34\%). Thirty-six percent experienced closed or positive surgical margin, and $26 \%$ were $\mathrm{ECE}^{+}$. The other risk factors of lymphovascular space involvement (LVSI), perineural involvement (PNI), lymph-node involvement $\geq 2$, and clinical stage are listed in Table 1.

\section{Treatment outcomes}

The mean follow-up time was $49.8 \pm 4.2 \mathrm{~ms}$ (range 4-70 ms, 95\% confidence interval 41.6-57.9). The median dose of radiation was 66 Gy. The actuarial 3- and 4-year OS, DFS, LRC, and MFS rates were $71.5 \%, 59.0 \%, 72.1 \%$, and $83.9 \%$, and $59.7 \%, 59.0 \%$, and $66.1 \% 83.9 \%$, respectively. (Figure 1A and B) The 4-year LRC rates for oral tongue and buccal mucosa cancer were $88.3 \%$ and $37.1 \%$, respectively $(P=0.012)$ (Figure 1C). The 4-year LRC rates of infield failure and out-of-field failure were $70.7 \%$ and $95.6 \%$, respectively (Figure 1D and E). The 4-year local and regional
Table I Patient characteristics

\begin{tabular}{|c|c|}
\hline \multirow[t]{2}{*}{ Variable } & \multirow{2}{*}{$\begin{array}{l}\text { Helical tomotherapy } \\
(n=53) \\
\text { Patients, } n\end{array}$} \\
\hline & \\
\hline \multicolumn{2}{|l|}{ Age (years) } \\
\hline Mean & 51 \\
\hline Range & $24-73$ \\
\hline \multicolumn{2}{|l|}{ Sex } \\
\hline Male & $50(94.3 \%)$ \\
\hline Female & $3(5.7 \%)$ \\
\hline \multicolumn{2}{|l|}{ Subsite } \\
\hline Oral tongue & $28(52.8 \%)$ \\
\hline Buccal mucosa & $18(34.0 \%)$ \\
\hline Alveolar ridge & $5(9.4 \%)$ \\
\hline Retromolar trigone & I (I.9\%) \\
\hline Floor of the mouth & I (I.9\%) \\
\hline Hard palate & 0 \\
\hline Lip & 0 \\
\hline \multicolumn{2}{|l|}{ Pathology } \\
\hline Squamous cell carcinoma & $53(100 \%)$ \\
\hline \multicolumn{2}{|l|}{ Resection-margin status } \\
\hline Close & $19(35.8 \%)$ \\
\hline Negative & $34(64.2 \%)$ \\
\hline \multicolumn{2}{|l|}{ Extracapsular spread } \\
\hline Positive & $14(26.4 \%)$ \\
\hline Negative & $39(73.6 \%)$ \\
\hline \multicolumn{2}{|l|}{ Perineural involvement } \\
\hline Positive & $4 \mathrm{I}(77.4 \%)$ \\
\hline Negative & $12(22.6 \%)$ \\
\hline \multicolumn{2}{|c|}{ Lymphovascular space involvement } \\
\hline Positive & $30(56.6 \%)$ \\
\hline Negative & $23(43.4 \%)$ \\
\hline \multicolumn{2}{|l|}{ Lymph-node involvement $\geq 2$} \\
\hline Positive & $22(4 I .5 \%)$ \\
\hline Negative & 31 (58.5\%) \\
\hline \multicolumn{2}{|l|}{ Pathology stage } \\
\hline \multicolumn{2}{|l|}{ Tumor stage } \\
\hline Stage I & $6(11.3 \%)$ \\
\hline Stage II & $8(15.1 \%)$ \\
\hline Stage III & $10(18.9 \%)$ \\
\hline Stage IVA & $29(54.7 \%)$ \\
\hline Stage IVB & 0 \\
\hline \multicolumn{2}{|l|}{ Primary tumor stage } \\
\hline $\mathrm{TI}$ & $8(15.1 \%)$ \\
\hline $\mathrm{T} 2$ & $20(37.7 \%)$ \\
\hline T3 & $10(18.9 \%)$ \\
\hline $\mathrm{T} 4 \mathrm{a}$ & $15(28.3 \%)$ \\
\hline $\mathrm{T} 4 \mathrm{~b}$ & 0 \\
\hline \multicolumn{2}{|l|}{ Regional lymph-node stage } \\
\hline No & $23(43.4 \%)$ \\
\hline NI & $5(9.4 \%)$ \\
\hline $\mathrm{N} 2 \mathrm{a}$ & $7(13.2 \%)$ \\
\hline $\mathrm{N} 2 \mathrm{~b}$ & $16(30.2 \%)$ \\
\hline $\mathrm{N} 2 \mathrm{c}$ & $2(3.8 \%)$ \\
\hline N3 & 0 \\
\hline \multicolumn{2}{|c|}{ Adjuvant concurrent chemotherapy } \\
\hline Yes & 49 (92.5\%) \\
\hline No & $4(7.5 \%)$ \\
\hline \multicolumn{2}{|l|}{ Radiation-therapy dose } \\
\hline Median (range) & 66 Gy (56-70.2 Gy) \\
\hline
\end{tabular}


control survival rates were $76.4 \%$ and $94.3 \%$, respectively (Figure $1 \mathrm{~F}$ and $\mathrm{G}$ ). Local recurrence primarily influenced the 4-year LRC rate $(P<0.01$, Figure $1 \mathrm{H})$.

\section{Locoregional failures}

Eleven (20.8\%) patients experienced locoregional failure. The median time of failure was 7 months. Infield failure was
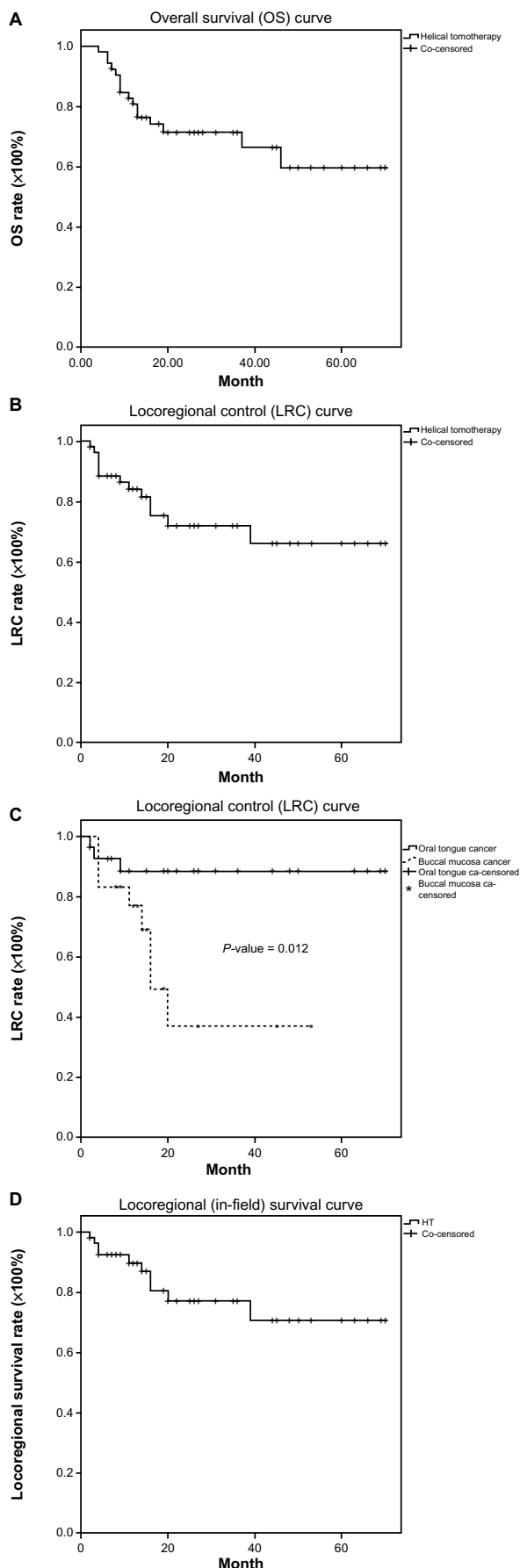

six of $53(11.3 \%)$ in the primary area and three of $53(5.7 \%)$ in the regional lymph-node area. No marginal failure was noted. Two of 53 (3.8\%) experienced with out-of-field failure. Of eleven patients, $63.6 \%$ were $\mathrm{PNI}^{+}$or $\mathrm{LVSI}^{+}$. Moreover, 54.5\% were $\mathrm{PNI}^{+}$and $\mathrm{LVSI}^{+}$simultaneously (Table 2). Patient 10, with right-side oral tongue cancer with operative margin close, $\mathrm{ECE}^{+}, \mathrm{PNI}^{+}, \mathrm{LVSI}^{+}$, and $\mathrm{T} 2 \mathrm{~N} 2 \mathrm{~b}$, was treated with
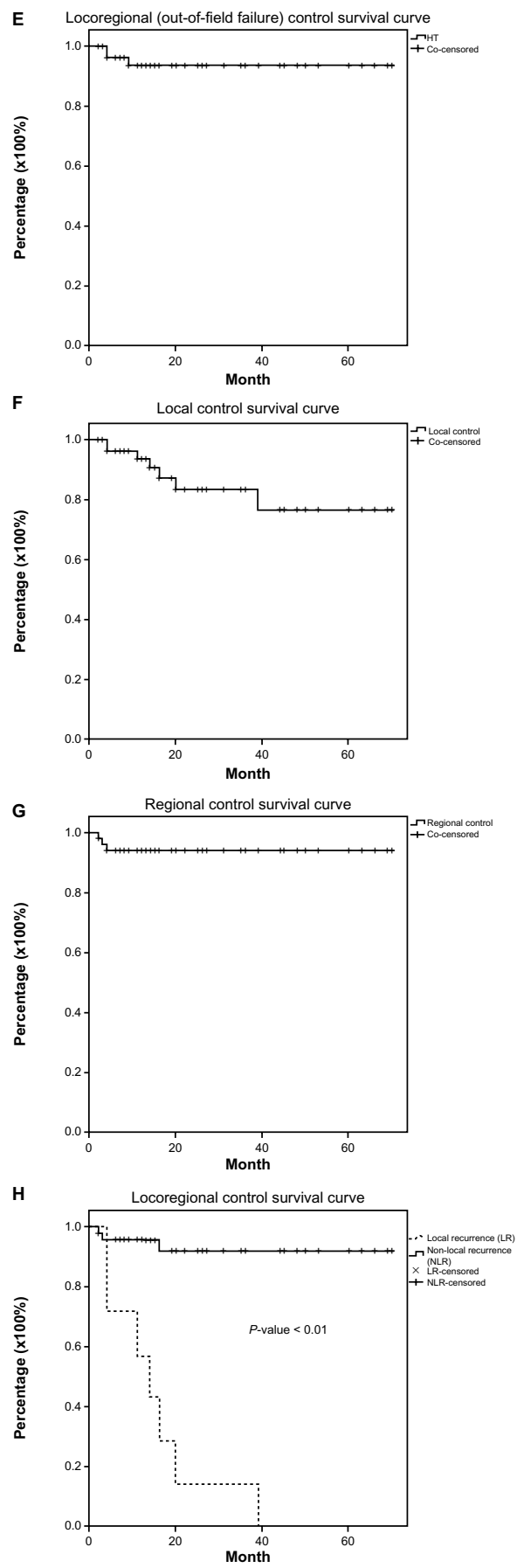

Figure I Kaplan-Meier estimates of (A) 4-year overall survival rate, (B) 4-year locoregional control rate, (C) 4-year locoregional control rate for oral tongue and buccal mucosa cancer, (D) 4-year locoregional (infield) control survival rate, (E) 4-year locoregional (out-of-field) control survival rate, (F) 4-year local control survival rate, (G) 4-year regional control survival rate, and $(\mathbf{H})$ 4-year regional control survival rate for postoperative oral cavity cancer patients treated with postoperative helical tomotherapy (HT), with or without concurrent chemotherapy. 


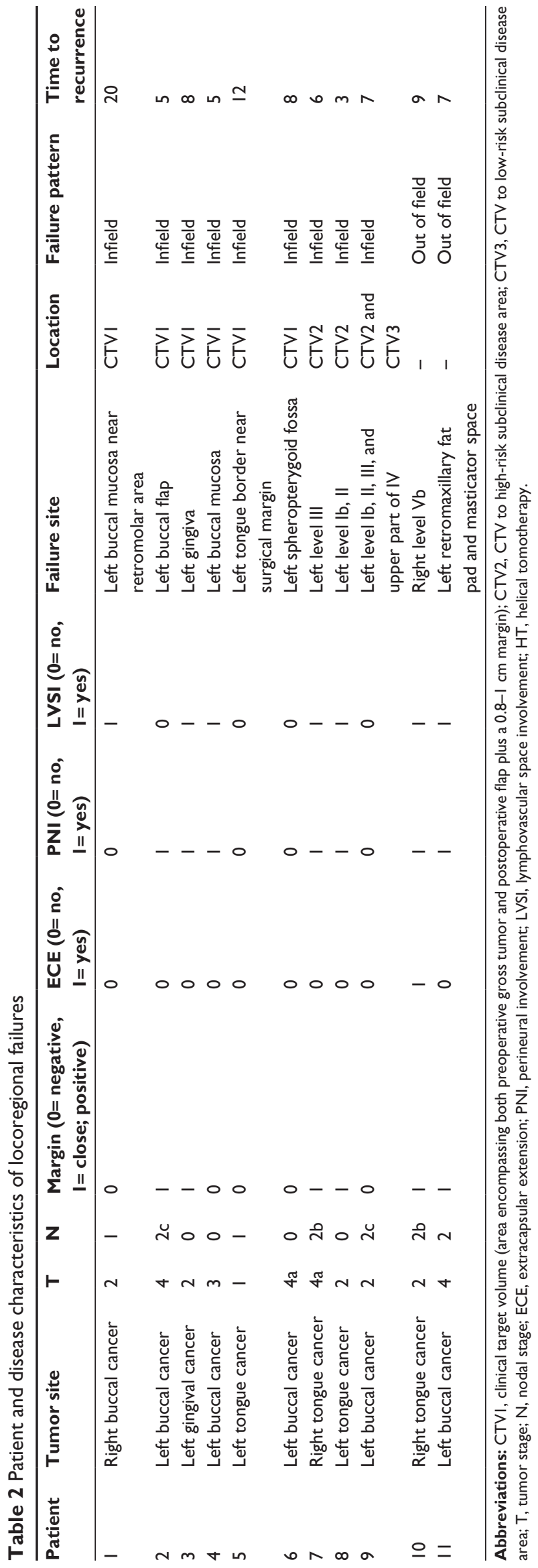

HT and had out-of-field failure in level Vb (Figure 2A). In patient 11, with left-side buccal mucosa cancer with operative margin close, $\mathrm{PNI}^{+}, \mathrm{LVSI}^{+}$, and T4N2, out-of-field failure occurred in the left side retromaxillary fat pad and masticator space (Figure 2C).

\section{Toxicities}

During CCRT, there was no grade 3 acute toxicity for xerostomia or body-weight loss. The rates of grade 3 dermatitis, mucositis, dysphagia, anemia, leucopenia, and thrombocytopenia were $11 \%, 34 \%, 13 \%, 2 \%, 9 \%$, and $0 \%$, respectively. The rate of grade 4 leucopenia was $2 \%$. Only two (5\%) patients suffered fistula formation after treatment (Table 3). The incidence of trismus and xerostomia at posttreatment 6 months versus 12 months versus 24 months versus 36 months versus 48 months was grade 1 (30.8\% versus $40.0 \%$ versus $70.0 \%$ versus $69.2 \%$ versus $71.4 \%$ and $66.7 \%$ versus $82.1 \%$ versus $90.0 \%$ versus $92.3 \%$ versus $100.0 \%$ ) and grade $2(56.4 \%$ versus $53.3 \%$ versus $30.0 \%$ versus $30.8 \%$ versus $28.6 \%$ and $33.3 \%$ versus $17.9 \%$ versus $10.0 \%$ versus $7.7 \%$ versus $0.0 \%$ ), respectively. Grade 3 trismus was $12.8 \%$ versus $6.7 \%$ versus $0.0 \%$ versus $0.0 \%$ versus $0.0 \%$, and there was no grade 3 xerostomia (Figure 3A and B).

\section{Discussion}

IMRT has recently become a popular technique for postoperative OCC, and encouraging results for 2- and 3-year LRC rates ranging from $53 \%$ to $91 \%$ have reported ${ }^{1-3,17-20}$ (Table 4). In head and neck cancer, ECE ${ }^{+}$, PNI, LVSI, pT3-4, and two positive nodes were categorized as important prognostic factors. The proportions of our patients with pT3-4 (47\%), PNI (77\%), and LVSI (57\%) were higher than those in other IMRT reports. In the current study, the actuarial 3-year and 4-year LRC rates were $72.1 \%$ and $66.1 \%$, respectively. Our data were compatible with previous reports.

The percentage of buccal cancer $(34 \%)$ in the current study was higher than in others $(0 \%-23 \%)$, except for the report by Chen et al. ${ }^{1}$ Local control of OCC is worse than that for head and neck cancer. ${ }^{21,22}$ In addition, local recurrence at 3 years after primary treatment for the gingiva-alveolarbuccal complex, lip, and hard palate was as high as $54 \%$, and regional failure was $11 \%{ }^{23}$ Lin et $\mathrm{al}^{24}$ reported that 5 -year LRC rates for SCC of the buccal mucosa were poor (36\%). T3/4 and node-positive cancer predicted a poorer survival rate, as noted in their report. Additionally, stage IV and node involvement in SCC of the buccal mucosa were also predictors for poor OS. ${ }^{25}$ In the current study, buccal mucosa cancer had a poor LRC rate (Figure 1C). For buccal cancer, 

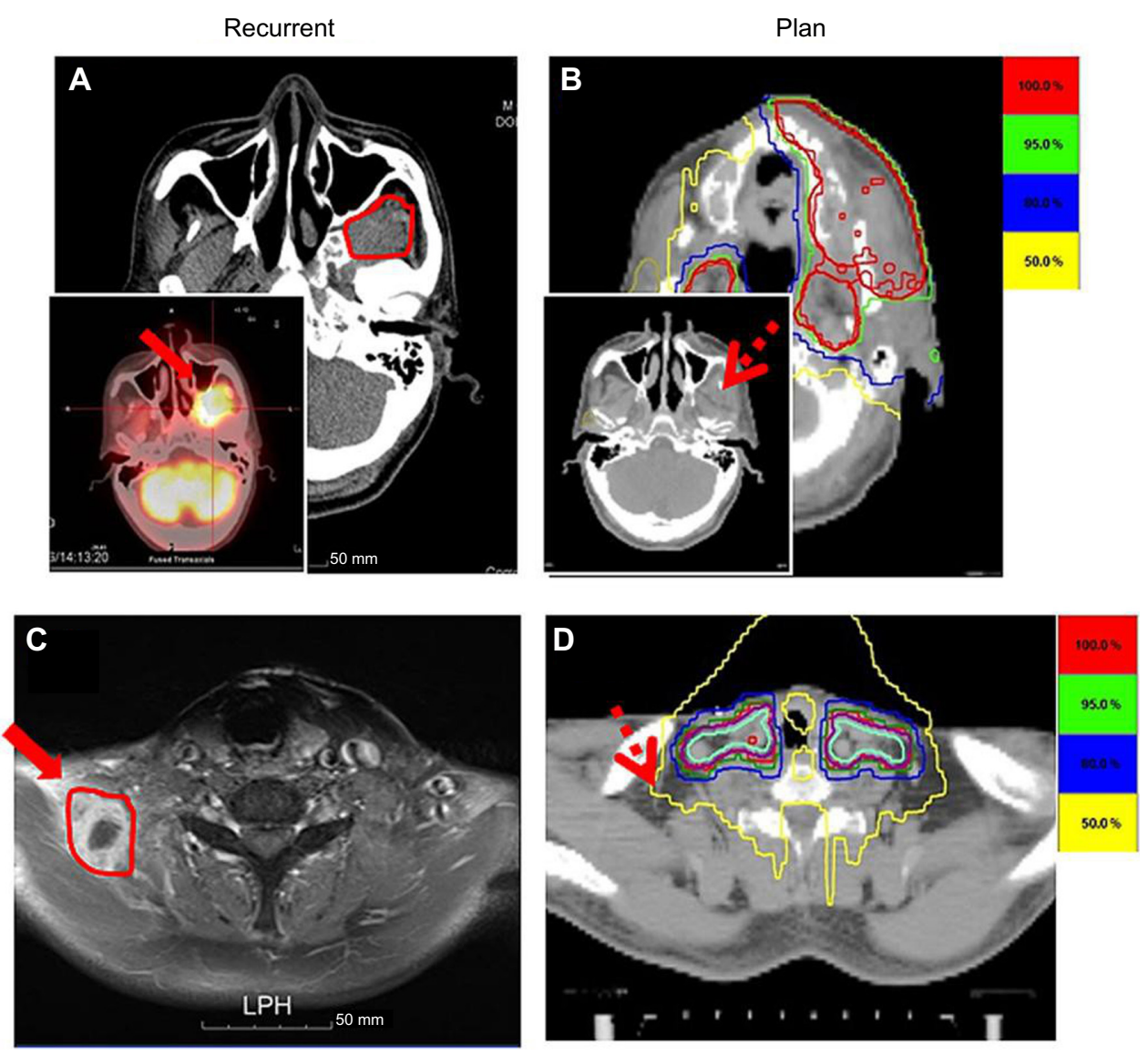

Figure 2 (A-D) Failure patterns in helical tomotherapy (HT) patients. (A) For patient 10, a case of left side buccal mucosa cancer with operative margin close, perineural invasion $\left(\mathrm{PNI}^{[+]}\right)$, lymphovascular space involvement $\left(\mathrm{LVSI}^{[+]}\right)$, and $\mathrm{T} 4 \mathrm{~N} 2$, treated with $\mathrm{HT}$, out-of-field failure occurred in ipsilateral retromaxillary fat pad and masticator space (circled red area and solid red arrow show location of recurrence). (B) original plan with no coverage of these areas was noted (red dotted arrow shows the area of missing targeting). (C) For patient II, a case of right-side oral tongue cancer with operative margin close, extracapsular extension (+), $\mathrm{PNI}{ }^{+}$, $\mathrm{LVSI}^{+}$, and $\mathrm{T}_{2} \mathrm{~N}_{2} \mathrm{~b}$ treated with $\mathrm{HT}$, ipsilateral out-field failure occurred in level $\mathrm{Vb}$ (circled red area and solid red arrow show area of recurrence). (D) The original plan was selectively targeted without level $\mathrm{Vb}$ coverage (red dotted arrow shows areas of inadequate targeting).

Abbreviation: $\mathrm{LPH}$, left, posterior, head.

we found a higher percentage than other reports (34\%), with more than $30 \%$ of T3/4 and around $60 \%$ of lymph nodes positive, and $40 \%$ at stage IV.

The character of locoregional failure in OCC is quick, shorter than 1 year. We noted the median time for those with locoregional failure was 7 months, which was similar to Daly et al (8.1 months). ${ }^{19}$ Bachar et al found 19 of 70 (27\%) patients experienced local failure and six $70(9 \%)$ patients had regional recurrence. ${ }^{26}$ Diaz et al reported an overall recurrence rate of $45 \%$ and a local recurrence rate of $32 \% .{ }^{25}$ Ghoshal et al documented a $2 \%$ regional recurrence rate (two of 100 patients). ${ }^{27}$ Most locoregional failures here were infield (nine, 17.0\%). The 4-year infield locoregional control rate was lower than the out-of-field locoregional control rate (Figure $1 F$ and $G$ ).

Chan et al reported that 12 of $38(32 \%)$ patients had marginal or out-of-field locoregional recurrences following postoperative IMRT for OCC. ${ }^{28}$ The rate of marginal or out-of-field failure for head and neck patients treated with IMRT was $10.8 \%-15.1 \%{ }^{4,19}$ In the current study, no marginal failure and only $4 \%$ out-of-field failure were noted. The data showed the benefits of image-guided modality with daily check using $3 \mathrm{~mm}$ as PTV margin could decrease marginal or out-of-field failure potential.

Murthy et al noted that the 3-year local recurrence rate of gingiva-alveolar-buccal complex, lip, and hard palate cancer after primary treatment was as high as $54 \%{ }^{23}$ Malignant epithelia contain cancer stem or clonogenic cells with regenerative abilities under cytotoxic stress that tend to repopulate tumors with very short stem cell-cycle times during the course of RT, and may become a major cause of RT failure. ${ }^{29,30}$ Furthermore, the cancer stem cell markers, integrin- $\beta 1$ and Oct4, linked with resistance to RT for squamous cell head and neck cancers with poor prognostic outcome, have been noted recently. ${ }^{31}$ Additionally, tumor 
Table 3 Acute toxicities for oral cavity cancer patients treated with helical tomotherapy

\begin{tabular}{|c|c|}
\hline Variable & $\begin{array}{l}\text { Helical tomotherapy } \\
(n=53)\end{array}$ \\
\hline \multicolumn{2}{|c|}{ *Xerostomia (acute) } \\
\hline tGr I & 34 (64.2\%) \\
\hline Gr 2 & $19(35.8 \%)$ \\
\hline Gr 3 & 0 \\
\hline Gr 4 & 0 \\
\hline Gr 5 & 0 \\
\hline \multicolumn{2}{|l|}{ Mucositis } \\
\hline Gr I & $5(9.4 \%)$ \\
\hline Gr 2 & 30 (56.5\%) \\
\hline Gr 3 & 18 (33.9\%) \\
\hline Gr 4 & 0 \\
\hline Gr 5 & 0 \\
\hline \multicolumn{2}{|l|}{ Dermatitis } \\
\hline Gr I & 25 (47.2\%) \\
\hline Gr 2 & $22(41.5 \%)$ \\
\hline Gr 3 & $6(11.3 \%)$ \\
\hline Gr 4 & 0 \\
\hline Gr 5 & 0 \\
\hline \multicolumn{2}{|c|}{ Body-weight loss } \\
\hline Gr I & 42 (79.2\%) \\
\hline Gr 2 & II (20.8\%) \\
\hline Gr 3 & 0 \\
\hline Gr 4 & 0 \\
\hline Gr 5 & 0 \\
\hline \multicolumn{2}{|l|}{ Dysphagia } \\
\hline Gr I & 40 (75.5\%) \\
\hline Gr 2 & $6(11.3 \%)$ \\
\hline Gr 3 & 7 (I3.2\%) \\
\hline Gr 4 & 0 \\
\hline Gr 5 & 0 \\
\hline \multicolumn{2}{|c|}{ Fistula formation } \\
\hline No & $5 \mathrm{I}(94.7 \%)$ \\
\hline Yes & $2(5.3 \%)$ \\
\hline \multicolumn{2}{|l|}{ Anemia } \\
\hline Gr I & 45 (84.9\%) \\
\hline Gr 2 & $7(13.2 \%)$ \\
\hline Gr 3 & I (1.9\%) \\
\hline Gr 4 & 0 \\
\hline Gr 5 & 0 \\
\hline \multicolumn{2}{|c|}{ Leucopenia } \\
\hline Gr I & 38 (7I.7\%) \\
\hline Gr 2 & $9(17.0 \%)$ \\
\hline Gr 3 & 5 (9.4\%) \\
\hline Gr 4 & I (1.9\%) \\
\hline Gr 5 & 0 \\
\hline \multicolumn{2}{|c|}{ Thrombocytopenia } \\
\hline Gr I & $51(96.2 \%)$ \\
\hline Gr 2 & $2(3.8 \%)$ \\
\hline Gr 3 & 0 \\
\hline Gr 4 & 0 \\
\hline Gr 5 & 0 \\
\hline
\end{tabular}

Notes: *Acute toxicity defined as occurring $<90$ days after beginning radiation therapy; 'grade of toxicity as per Common Terminology Criteria for Adverse Events version 3.0.
A Incidences of trismus grading according to time sequence

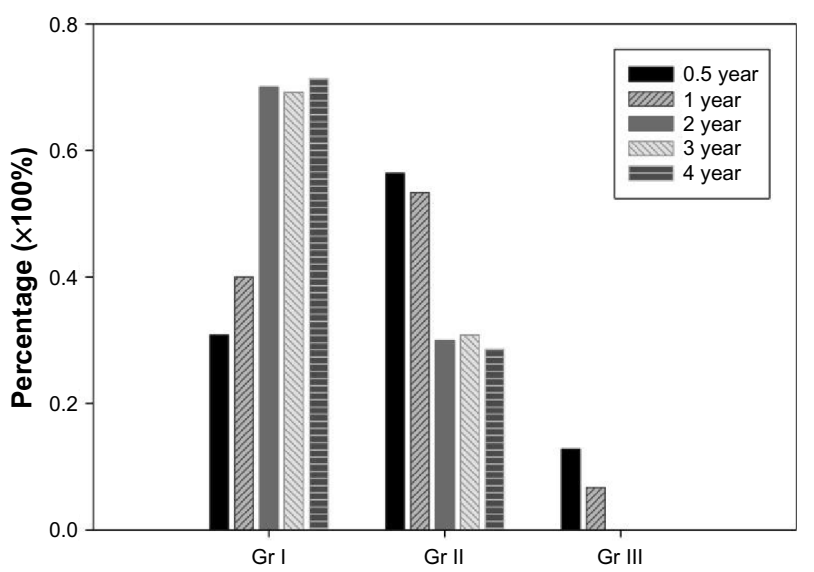

B Incidences of xerostomia grading according to time sequence

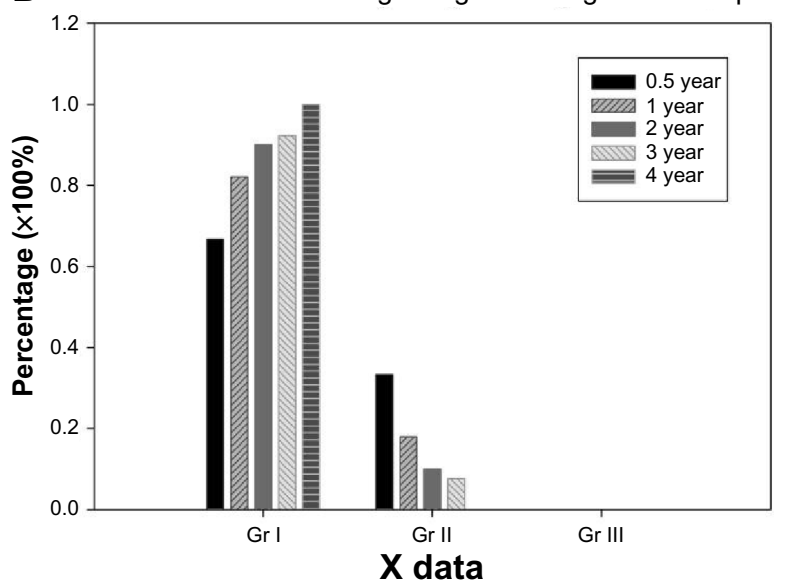

Figure 3 Incidence of late toxicities for (A) trismus and (B) xerostomia, according to the time sequence for oral cavity cancer patients receiving adjuvant helical tomotherapy.

hypoxia has been shown to be an important predictor of response to therapy and outcome. ${ }^{32,33}$ In the current study, even using image-guided modality, the infield failure rate in the primary and regional lymph-node area was $11 \%$ and $6 \%$, respectively. Furthermore, the median time of failure was 7 months. Possible reasons may be cancer stem cells or tumor hypoxia. Targeting cancer stem cell molecules with monoclonal antibodies or pharmaceutical agents, or using hypoxia imaging to address hypoxic subvolumes through dose painting delivering higher doses to potentially more radioresistant parts of a tumor, may provide chances to overcome infield failure of OCC in future. ${ }^{31,34}$

A patient with ipsilateral masticator space recurrence (Figure 2A and B) and another with unexpected recurrence in level $\mathrm{V}$ were noted (Figure $2 \mathrm{C}$ and $\mathrm{D}$ ). Retrograde perineural tracking toward the masseter ${ }^{3,19}$ or lymphatics might become altered and unpredictable after surgery, ${ }^{35}$ which could have placed these regions at risk for failure. Five-year actuarial LRC rates were significantly worse in 
Table 4 Four-year estimated overall survival (OS), disease-free survival (DFS), locoregional progress-free survival (LRPF), and distant metastasis-free (DMF) rate of postoperative helical tomotherapy (HT) with or without chemotherapy (CT) for high-risk oral cavity cancer at the Far Eastern Memorial Hospital (FEMH) compared with selected published series treated by intensity-modulated radiation therapy (IMRT)

\begin{tabular}{|c|c|c|c|c|c|c|c|}
\hline $\begin{array}{l}\text { Selected published } \\
\text { series }\end{array}$ & $\begin{array}{l}\text { Postoperative } \\
\text { patients, } \mathbf{n}\end{array}$ & CT & T3-4 & $\begin{array}{l}\mathrm{LN} \text { involvement } \\
\geq 2 \text { positive }\end{array}$ & Stage III, IV & $\begin{array}{l}\text { Resection margin positive } \\
\text { or close }\end{array}$ & ECE \\
\hline Studer et $\mathrm{al}^{17}$ & 28 & $78 \%$ & $32 \%$ & $57 \%$ & $68 \%$ & - & - \\
\hline Yao et $\mathrm{al}^{3}$ & 55 & $11 \%$ & $56 \%$ & $33 \%$ & $91 \%$ & - & - \\
\hline Gomez et $\mathrm{al}^{2}$ & 35 & $29 \%$ & - & - & $80 \%$ & - & - \\
\hline Chen et al' & 22 & $9 \%$ & - & $32 \%$ & $100 \%$ & $5 \%$ & $32 \%$ \\
\hline Sher et $\mathrm{al}^{20}$ & 31 & $77 \%$ & $26 \%$ & $30 \%$ & $64 \%$ & $17 \%$ & $20 \%$ \\
\hline Daly et al ${ }^{19}$ & 30 & $66 \%$ & $44 \%$ & $7 \%$ & $76 \%$ & $63 \%$ & $35 \%$ \\
\hline Geretschläger et $\mathrm{al}^{4}$ & 53 & $47 \%$ & $38 \%$ & - & $70 \%$ & $72 \%$ & $32 \%$ \\
\hline Moon et a $\left.\right|^{18}$ & 23 & $9 \%$ & $39 \%$ & $52 \%$ & $87 \%$ & - & - \\
\hline Hsieh et $\mathrm{al}^{8}$ & 19 & $84 \%$ & $68 \%$ & $58 \%$ & $95 \%$ & $53 \%$ & $42 \%$ \\
\hline FEMH & 53 & $87 \%$ & $47 \%$ & $47 \%$ & $74 \%$ & $36 \%$ & $26 \%$ \\
\hline
\end{tabular}

OCC patients with PNI ${ }^{36}$ There were $64 \%$ who were $\mathrm{PNI}^{+}$or $\mathrm{LVSI}^{+}$. Moreover, 55\% were $\mathrm{PNI}^{+}$concurrent with $\mathrm{LVSI}^{+}$in our study. Our observations also reflected previous suggestions, even using HT. Nerves at risk in the tumor bed or tumor adjacent to pterygoid muscle should be covered in a retrograde fashion within the RT field, and the selective approach should be very cautious, especially in the setting of lymphatics that might become altered after surgery or $\mathrm{PNI}^{+}$and $\mathrm{LVSI}^{+}$disease.

Mucosa is part of the CTV for OCC, and it is mucosal reactions that dominate acute reactions; therefore, grade 3 mucositis was as high as $34 \%$, even with the highly conformal techniques provided by HT (Table 3 ). Nevertheless, for acute toxicities, no grade 3 xerostomia or body-weight loss was noted. Grade 3 dermatitis and dysphagia occurred with postoperative IMRT concurrent with chemotherapy at a rate of $7 \%-10 \%$ and $24 \%-83 \%$, respectively. ${ }^{18-20}$ However, the rates of grade 3 dermatitis and dysphagia for patients treated with adjuvant HT were $11 \%$ and $13 \%$, respectively.

Saarilahti et $\mathrm{al}^{37}$ found the median basal saliva flow rate was $0.13 \mathrm{~mL} / \mathrm{minute}$ prior to $\mathrm{RT}$, and 0.04 and $0.07 \mathrm{~mL} / \mathrm{minute}$ at 6 and 12 months after RT, respectively. Recently, a Phase III trial proved parotid-sparing IMRT caused better recovery of saliva secretion than conventional RT. ${ }^{10}$ They found grade 2 or worse xerostomia at 12 months and 24 months was $38 \%$ and $29 \%$, respectively. Here, the rates of patients treated with HT experiencing grade 2 late xerostomia at 12 months and 24 months were $18 \%$ and $10 \%$, respectively. HT showed a trend of decreasing acute and late toxicities to the salivary gland (Figure $3 \mathrm{~B}$ ).

Trismus is one of the long-term sequelae of RT for head and neck cancer. The prevalence of trismus for head and neck cancer after treatment could as high as $42 \%{ }^{38}$ Wang et al measured the maximal interincisal distance (MID), and demonstrated that MID decreased gradually by $2.4 \%$, $0.2 \%$, and $0.1 \%$ after RT at $1-9$ months, $12-24$ months, and 24-48 months, respectively. ${ }^{39}$ For nasopharyngeal carcinoma (NPC) patients treated with IMRT, the average MID before IMRT and at 12 months post-IMRT was $46.2 \mathrm{~mm}$ and 45.4 mm. ${ }^{11}$ Compared with baseline MID levels for IMRT-treated NPC patients, the differences for normalized MID levels between 6 months to 5 years was only $4 \% .^{12}$ Here, the incidence of grades 1, 2, and 3 trismus show an inverse trend to the time sequence with post-HT treatment (Figure 3A). Additionally, the ratios of grade 1 and 2 trismus treated by HT were stationary after 24-48 months. Our results provide evidence of decreasing late complications of HT by better normal-tissue sparing and sharper dose gradients..$^{7-9}$ In addition, the data support no more significant decreases at time points beyond 1 year after RT. ${ }^{12,39}$

This study has several limitations, most of which are related to its retrospective nature. However, all patients were reviewed by the multidisciplinary tumor board, and all individuals were treated with a consistent treatment philosophy. Additionally, the case numbers of HT were limited. Third, the current study lacks objective data of MID for trismus and saliva flow rate for xerostomia. However, trismus and xerostomia grades based on the CTCAE abstracted from the medical record could have diminished the insufficiency of objective measurement in the current study. Finally, toxicity data were not prospectively collected but rather abstracted from the medical record. Such a process is limited by the underlying inadequacies of medical documentation when used for research purposes. 
Table 4 (Continued)

\begin{tabular}{|c|c|c|c|c|c|c|c|c|c|}
\hline \multirow[t]{2}{*}{ PNI } & \multirow[t]{2}{*}{ LVSI or VEs } & \multirow{2}{*}{$\begin{array}{l}\text { Postoperative } \\
\text { modality }\end{array}$} & \multicolumn{2}{|c|}{ Percentage of } & \multirow[t]{2}{*}{ Follow-up } & \multirow[t]{2}{*}{ OS } & \multirow[t]{2}{*}{ DFS } & \multirow[t]{2}{*}{ LRPF } & \multirow[t]{2}{*}{ DMF } \\
\hline & & & Oral tongue & Buccal mucosa & & & & & \\
\hline- & - & IMRT & - & - & 2 years & $83 \%$ & $87 \%$ & $91 \%$ & $95 \%$ \\
\hline- & - & IMRT & $36 \%$ & $11 \%$ & 3 years & $68 \%$ & $74 \%$ & $82 \%$ & $89 \%$ \\
\hline- & - & IMRT & $31 \%$ & $23 \%$ & 3 years & $74 \%$ & $64 \%$ & $77 \%$ & $85 \%$ \\
\hline- & - & IMRT & $9 \%$ & $82 \%$ & 3 years & $67 \%$ & $64 \%$ & - & - \\
\hline $43 \%$ & $17 \%$ & IMRT & $55 \%$ & $5 \%$ & 2 years & $85 \%$ & $82 \%$ & $91 \%$ & $94 \%$ \\
\hline $50 \%$ & - & IMRT & $57 \%$ & $0 \%$ & 3 years & $60 \%$ & - & $53 \%$ & $81 \%$ \\
\hline- & - & IMRT & $41 \%$ & - & 3 years & $73 \%$ & - & $79 \%$ & $90 \%$ \\
\hline- & - & IMRT/HT & $83 \%$ & $0 \%$ & 3 years & $61 \%$ & $61 \%$ & $82 \%$ & $66 \%$ \\
\hline $74 \%$ & $68 \%$ & $\mathrm{HT}$ & $47 \%$ & $32 \%$ & 2 years & $94 \%$ & $84 \%$ & $92 \%$ & $94 \%$ \\
\hline \multirow[t]{2}{*}{$77 \%$} & $57 \%$ & $\mathrm{HT}$ & $53 \%$ & $34 \%$ & 3 years & $72 \%$ & $59 \%$ & $72 \%$ & $84 \%$ \\
\hline & & & & & 4 years & $60 \%$ & $59 \%$ & $66 \%$ & $84 \%$ \\
\hline
\end{tabular}

Abbreviations: LN, lymph node; ECE, extracapsular extension; PNI, perineural involvement; LVSI, lymphovascular space involvement; VE, vascular embolism.

In conclusion, HT may provide tumor control and a less severe morbidity profile, especially in life quality-impairing xerostomia and trismus, in comparison with historical data for postoperative high- and intermediate-risk OCC patients. More careful and accurate target-volume delineation is essential to the success of treatment, even with image-guided techniques.

\section{Acknowledgments}

This study was supported by grants from the Far Eastern Memorial Hospital (FEMH-2013-C-014; FEMH101-2314B418-010-MY3). We are indebted to Yin-Shin Tsai and Mei-Hui Lu for data collection.

\section{Disclosure}

The authors report no conflicts of interest in this work.

\section{References}

1. Chen WC, Hwang TZ, Wang WH, et al. Comparison between conventional and intensity-modulated post-operative radiotherapy for stage III and IV oral cavity cancer in terms of treatment results and toxicity. Oral Oncol. 2009;45(6):505-510.

2. Gomez DR, Zhung JE, Gomez J, et al. Intensity-modulated radiotherapy in postoperative treatment of oral cavity cancers. Int J Radiat Oncol Biol Phys. 2009;73(4):1096-1103.

3. Yao M, Chang K, Funk GF, et al. The failure patterns of oral cavity squamous cell carcinoma after intensity-modulated radiotherapy the University of Iowa experience. Int J Radiat Oncol Biol Phys. 2007;67(5):1332-1341

4. Geretschläger A, Bojaxhiu B, Crowe S, et al. Outcome and patterns of failure after postoperative intensity modulated radiotherapy for locally advanced or high-risk oral cavity squamous cell carcinoma. Radiat Oncol. 2012;7(1):175.

5. van Vulpen M, Field C, Raaijmakers CP, et al. Comparing step-and-shoot IMRT with dynamic helical tomotherapy IMRT plans for head-and-neck cancer. Int J Radiat Oncol Biol Phys. 2005;62(5):1535-1539.

6. Fiorino C, Dell'Oca I, Pierelli A, et al. Significant improvement in normal tissue sparing and target coverage for head and neck cancer by means of helical tomotherapy. Radiother Oncol. 2006;78(3):276-282.
7. Shueng PW, Wu LJ, Chen SY, et al. Concurrent chemoradiotherapy with helical tomotherapy for oropharyngeal cancer: a preliminary result. Int J Radiat Oncol Biol Phys. 2010;77(3):715-721.

8. Hsieh CH, Kuo YS, Liao LJ, et al. Image-guided intensity modulated radiotherapy with helical tomotherapy for postoperative treatment of high-risk oral cavity cancer. BMC Cancer. 2011;11:37.

9. Shueng PW, Shen BJ, Wu LJ, et al. Concurrent image-guided intensity modulated radiotherapy and chemotherapy following neoadjuvant chemotherapy for locally advanced nasopharyngeal carcinoma. Radiat Oncol. 2011;6:95.

10. Nutting CM, Morden JP, Harrington KJ, et al. Parotid-sparing intensity modulated versus conventional radiotherapy in head and neck cancer (PARSPORT): a phase 3 multicentre randomised controlled trial. Lancet Oncol. 2011;12(2):127-136.

11. Hsiung CY, Huang EY, Ting HM, Huang HY. Intensity-modulated radiotherapy for nasopharyngeal carcinoma: the reduction of radiation-induced trismus. Br J Radiol. 2008;81(970):809-814.

12. Chen YY, Zhao C, Wang J, et al. Intensity-modulated radiation therapy reduces radiation-induced trismus in patients with nasopharyngeal carcinoma: a prospective study with $>5$ years of follow-up. Cancer. 2011;117(13):2910-2916.

13. Chao KS, Wippold FJ, Ozyigit G, Tran BN, Dempsey JF. Determination and delineation of nodal target volumes for head-andneck cancer based on patterns of failure in patients receiving definitive and postoperative IMRT. Int J Radiat Oncol Biol Phys. 2002;53(5): 1174-1184.

14. Bernier J, Cooper JS, Pajak TF, et al. Defining risk levels in locally advanced head and neck cancers: a comparative analysis of concurrent postoperative radiation plus chemotherapy trials of the EORTC (\#22931) and RTOG (\#9501). Head Neck. 2005;27(10):843-850.

15. Cooper JS, Pajak TF, Forastiere AA, et al. Postoperative concurrent radiotherapy and chemotherapy for high-risk squamous-cell carcinoma of the head and neck. N Engl J Med. 2004;350(19):1937-1944.

16. Chao KS, Ozyigit G, Tran BN, Cengiz M, Dempsey JF, Low DA. Patterns of failure in patients receiving definitive and postoperative IMRT for head-and-neck cancer. Int J Radiat Oncol Biol Phys. 2003;55(2):312-321.

17. Studer G, Zwahlen RA, Graetz KW, Davis BJ, Glanzmann C. IMRT in oral cavity cancer. Radiat Oncol. 2007;2:16.

18. Moon SH, Jung YS, Ryu JS, et al. Outcomes of postoperative simultaneous modulated accelerated radiotherapy for head-and-neck squamous cell carcinoma. Int J Radiat Oncol Biol Phys. 2011;81(1):140-149.

19. Daly ME, Le QT, Kozak MM, et al. Intensity-modulated radiotherapy for oral cavity squamous cell carcinoma: patterns of failure and predictors of local control. Int J Radiat Oncol Biol Phys. 2011;80(5):1412-1422. 
20. Sher DJ, Thotakura V, Balboni TA, et al. Treatment of oral cavity squamous cell carcinoma with adjuvant or definitive intensitymodulated radiation therapy. Int J Radiat Oncol Biol Phys. 2011;81(4): e215-e222.

21. Amdur RJ, Parsons JT, Mendenhall WM, Million RR, Stringer SP, Cassisi NJ. Postoperative irradiation for squamous cell carcinoma of the head and neck: an analysis of treatment results and complications. Int J Radiat Oncol Biol Phys. 1989;16(1):25-36.

22. Eisbruch A, Marsh LH, Dawson LA, et al. Recurrences near base of skull after IMRT for head-and-neck cancer: implications for target delineation in high neck and for parotid gland sparing. Int J Radiat Oncol Biol Phys. 2004;59(1):28-42.

23. Murthy V, Agarwal JP, Laskar SG, et al. Analysis of prognostic factors in 1180 patients with oral cavity primary cancer treated with definitive or adjuvant radiotherapy. J Cancer Res Ther. 2010;6(3):282-289.

24. Lin CS, Jen YM, Cheng MF, et al. Squamous cell carcinoma of the buccal mucosa: an aggressive cancer requiring multimodality treatment. Head Neck. 2006;28(2):150-157.

25. Diaz EM Jr, Holsinger FC, Zuniga ER, Roberts DB, Sorensen DM. Squamous cell carcinoma of the buccal mucosa: one institution's experience with 119 previously untreated patients. Head Neck. 2003;25(4): 267-273.

26. Bachar G, Goldstein DP, Barker E, et al. Squamous cell carcinoma of the buccal mucosa: outcomes of treatment in the modern era. Laryngoscope. 2012;122(7):1552-1557.

27. Ghoshal S, Mallick I, Panda N, Sharma SC. Carcinoma of the buccal mucosa: analysis of clinical presentation, outcome and prognostic factors. Oral Oncol. 2006;42(5):533-539.

28. Chan AK, Huang SH, Le LW, et al. Postoperative intensity-modulated radiotherapy following surgery for oral cavity squamous cell carcinoma: patterns of failure. Oral Oncol. 2013;49(3):255-260.

29. Marcu LG, Bezak E. Influence of stem-cell cycle time on accelerated re-population during radiotherapy in head and neck cancer. Cell Prolif. 2012;45(5):404-412.
30. Trott KR. Cell repopulation and overall treatment time. Int J Radiat Oncol Biol Phys. 1990;19(4):1071-1075.

31. Koukourakis MI, Giatromanolaki A, Tsakmaki V, Danielidis V, Sivridis E. Cancer stem cell phenotype relates to radio-chemotherapy outcome in locally advanced squamous cell head-neck cancer. $\mathrm{Br} J$ Cancer. 2012;106(5):846-853.

32. Brizel DM, Sibley GS, Prosnitz LR, Scher RL, Dewhirst MW. Tumor hypoxia adversely affects the prognosis of carcinoma of the head and neck. Int J Radiat Oncol Biol Phys. 1997;38(2):285-289.

33. Nordsmark M, Overgaard J. A confirmatory prognostic study on oxygenation status and loco-regional control in advanced head and neck squamous cell carcinoma treated by radiation therapy. Radiother Oncol. 2000;57(1):39-43.

34. Bittner MI, Grosu AL. Hypoxia in head and neck tumors: characteristics and development during therapy. Front Oncol. 2013;3:223.

35. Damast S, Wolden S, Lee N. Marginal recurrences after selective targeting with intensity-modulated radiotherapy for oral tongue cancer. Head Neck. 2012;34(6):900-906.

36. Hinerman RW, Mendenhall WM, Morris CG, Amdur RJ, Werning JW, Villaret DB. Postoperative irradiation for squamous cell carcinoma of the oral cavity: 35-year experience. Head Neck. 2004;26(11):984-994.

37. Saarilahti K, Kouri M, Collan J, et al. Intensity modulated radiotherapy for head and neck cancer: evidence for preserved salivary gland function. Radiother Oncol. 2005;74(3):251-258.

38. Johnson J, van As-Brooks CJ, Fagerberg-Mohlin B, Finizia C. Trismus in head and neck cancer patients in Sweden: incidence and risk factors. Med Sci Monit. 2010;16(6):CR278-CR282.

39. Wang CJ, Huang EY, Hsu HC, Chen HC, Fang FM, Hsiung CY. The degree and time-course assessment of radiation-induced trismus occurring after radiotherapy for nasopharyngeal cancer. Laryngoscope. 2005;115(8):1458-1460.
OncoTargets and Therapy

\section{Publish your work in this journal}

OncoTargets and Therapy is an international, peer-reviewed, open access journal focusing on the pathological basis of all cancers, potential targets for therapy and treatment protocols employed to improve the management of cancer patients. The journal also focuses on the impact of management programs and new therapeutic agents and protocols on

\section{Dovepress}

patient perspectives such as quality of life, adherence and satisfaction The manuscript management system is completely online and includes a very quick and fair peer-review system, which is all easy to use. Visit http://www.dovepress.com/testimonials.php to read real quotes from published authors. 